\title{
Sosyal ağ pazarlaması, çevrimiçi tüketici katılımı, satın alma niyeti ve marka sadakati arasındaki ilişkiler
}

\section{The relationships among social media marketing, online consumer engagement, purchase intention and brand loyalty}

\author{
Leyla Gödekmerdan Önder ${ }^{1}$
}

Arzu Deniz Çakıroğlu²

\author{
1 Dr. Öğr. Üyesi, Ufuk Üniversitesi, \\ Ankara, Türkiye \\ lngodekmerdan@gmail.com \\ ORCID: 0000-0003-1969-8843 \\ 2 Dr. Öğr. Üyesi, Giresun Üniversitesi, \\ Giresun, Türkiye \\ arzdnzaof@gmail.com
}

ORCID: 0000-0003-4260-0373

\section{SorumluYazar/Corresponding Author:}

Leyla Gödekmerdan Önder,

Ufuk Üniversitesi, Ankara, Türkiye

lngodekmerdan@gmail.com

Başvuru/Submitted: 21/06/2021

Revizyon/Revised: 30/07/2021

Kabul/Accepted: 5/08/2021

Yayın/Online Published: 25/09/2021
Öz

Bu çalışmanın amacı sosyal ağ pazarlaması, çevrimiçi tüketici katılımı, satın alma niyeti ve marka sadakati arasındaki ilişkileri incelemektir. Bu amaçla sosyal medyayı kullanan tüketicilere bir anket çalışması yapılmış ve sonuçlar irdelenmiştir. Araştırmadan elde edilen sonuçlara göre sosyal ağlarda yürütülen pazarlama faaliyetleri, tüketicilerin bu faaliyetlere katılımı, satın alma niyetleri ve markaya duyulan bağlılıkları arasında ilişkiler bulunmaktadır. Sosyal ağ pazarlaması faaliyetleri tüketicilerin katılımını ve satın alma niyetlerini etkilemektedir. Çevrimiçi katılım hem sadakat hem satın alma niyeti üzerinde etkilidir. Buna ek olarak marka bağlılığı satın alma niyetini pozitif yönde etkilemektedir.

Anahtar Kelimeler:Sosyal A $\breve{g}$ Pazarlaması, Çevrimiçi Tüketici Katılımı, Satın Alma Niyeti, Marka Sadakati

Jel Kodlari: M0, M1, M3

\begin{abstract}
The study investigates social media marketing, online consumer engagement, purchase intention, and brand loyalty. For that purpose, a survey is applied to consumers using social media and results are examined. According to results, there are relationships among social media marketing activities, online consumer engagement, purchase intention and brand loyalty. Social media marketing activities affect consumer engagement and purchase intention. Online engagement affects both loyalty and purchase intention. Additionally, brand loyalty affects positively purchase intention.
\end{abstract}

Keywords: Social Media Marketing, Online Consumer Engagement, Purchase Intention, Brand Loyalty

Jel Codes: M0, M1, M3

\footnotetext{
Atıf/Citation: Önder Gödekmerdan, L., \&Çakıroğlu Deniz, A., Sosyal ağ pazarlaması, çevrimiçi tüketici katılımı, satın alma niyeti ve marka sadakati arasındaki ilişkiler,bmij (2021) 9 (3):10451059, doi:

https://doi.org/10.15295/bmij.v9i3.1873
}

(C) 2021 The Author(s) 


\section{ExtendedAbstract}

The relationships among social media marketing, online consumer engagement, purchase intention and brand loyalty

\section{Literature}

One of the new concepts that has come into our lives due to the technological revolution in the world is social media. Social media is defined as online tools in which content, opinions, perspectives and media sharing can be carried out (Santosa,2020:1). Consumers have begun using these websites as a means of reaching the information quickly and rapidly. Businesses have taken part in these platforms for marketing their brands. Business' marketing activities on social networks provide target marketing. Consumers reach the information about the product or brand easily and quickly.

Additionally, marketing activities on social networks significantly affect consumers' product preferences and purchase intentions (Ahmed and Zahid, 2014:534). One thing that needs to be done to change consumer preferences is to attract consumers' attention by emphasizing contact points in marketing a product (Toor, Husnain and Hussain, 2017:177). This effort is referred to as consumer engagement. Today, this concept has been extended. It has been a concept focusing on consumer engagement by interacting with them and creating an emotional bond between the business and the consumer beyond purchase behaviour (Farook and Abeysekara, 2016, 116). One of the essential tools used to create this bond between the consumer and the business is social media platforms (Ahmed and Zahid, 2014:308). Providing consumer engagement through social network marketing ensure that quick and two-way communication is set, and trust, good intent and attachment develop between both parties (Muchardie, Yudiana and Gunawan, 2016, 83; Farook and Abeysekara,2016:115). Social media platforms are influential sources to motivate consumers on purchase intention or behaviour emotionally. The position created in consumers' minds regarding the business or brand via social network marketing activities helps consumers be convinced of purchase the products offered by the business. Directing the consumers' engagement process efficiently and professionally positively affects consumers' purchase behaviour (Barhemmati and Ahmad, 2015, 308). Brand loyalty is another concept to address with consumer engagement and purchase intention regarding online marketing activities. Creating positive attitudes towards the brand makes consumers more loyal by interactive brand experiences and a psychological link beyond purchase behaviour (Fernandes and Moreira, 2018, 275).

\section{Research purpose, design and method}

This study analyses the relationships among social network marketing activities, online consumer engagement, purchase intention, and brand loyalty. These relations were tested in a model by structural equation modelling. The universe of the study comprised consumers aged 18 years and overusing social media. Data were collected online through social networks. The convenience sampling method was used as the sampling method. A total of 557 surveys were obtained to be analyzed. SPSS 20 and LISREL 8.7 statistical programs were used in the analysis of the obtained data.

\section{Research model}

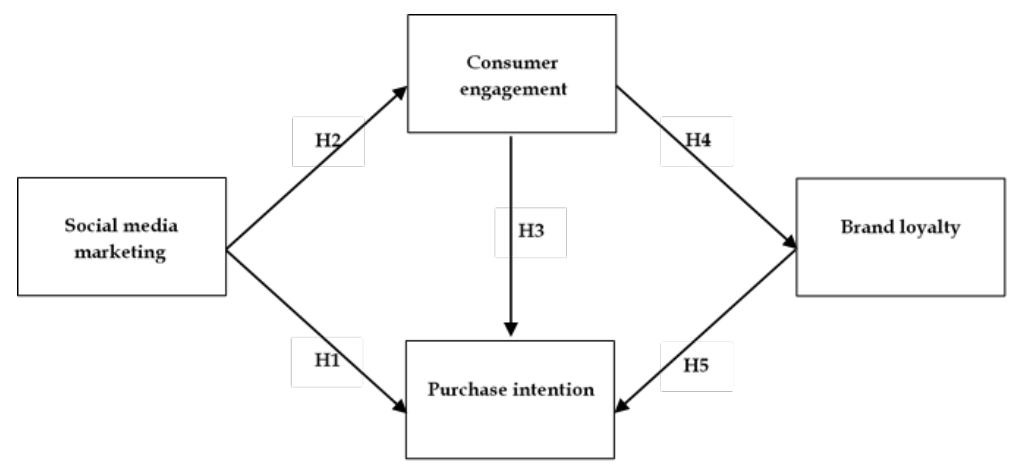

\section{Research hypotheses}

$\mathrm{H}_{1}$ : Social media marketing affects purchase intention positively.

$\mathrm{H}_{2}$ : Social media marketing affects consumer engagement positively.

$\mathrm{H}_{3}$ : Consumer engagement affects purchase intention positively.

$\mathrm{H}_{4}$ : Consumer engagement affects brand loyalty positively.

$\mathrm{H}_{5}$ : Brand loyalty affects purchase intention positively.

\section{Findings and discussion}

According to the results, social media activities affect online consumer engagement and purchase intention. Online consumer engagement has affected purchase intention and brand loyalty. Consumers' brand loyalty has a positive impact on purchase intention. All hypotheses of the study have been accepted. In line with the results obtained, recommendations have been offered to increase consumer engagement through marketing activities on social networks, affect purchase intentions and create brand loyalty. Businesses can increase online engagement by diversifying their marketing activities on social networks, sharing colourful, amusing, joyous, and intriguing photographs and videos, and organising contests, competitions and prizes. Ensuring online engagement can positively affect the consumers' purchase intentions to the product or brand and increase consumers' loyalty to the brand.

\section{Limitations of the article}

The study is applied to 18 overage people who are living in Ankara. Similar studies are applied for more consumer groups. Social media networks are investigated totally in this study. Future studies can be determined these variables in terms of different social media platforms. Different variables can be added to the research model. 


\section{Giriş}

Sosyal medya iletişim çağının birey ve örgütlere sunduğu en önemli araçlar arasında yer almaktadır. Kullanıcıların çevrimiçi olarak iletişim kurmalarına imkân veren buna ek olarak çeşitli paylaşımlarda bulunmalarını sağlayan sosyal ağlar da sosyal medyadaki kaynaklardan biridir. Günümüzde işletmeler ve tüketiciler sosyal ağları tüm dünyayı ilgilendiren haber ve bilgilere ulaşma, stratejiler geliştirme, yeni iş fırsatlarını değerlendirme, müşterilerle uzun vadeli ilişkiler kurma, marka imajı geliştirme vb. amaçlarla çok sık kullanmaya başlamışlardır. Tüketiciler sosyal ağlarda sadece gelişmeleri takip etmekle kalmayıp paylaşımlar da yapabilmektedir. Bu paylaşımlar genellikle çevrimiçi etkinliklere daha fazla katılma ve markaların gönderilerini beğenme, yorum yapma veya içerik oluşturma şeklinde ortaya çıkmaktadır. Çevrimiçi tüketici katılımı şeklinde tanımlanan bu bilişsel ve davranışsal faaliyetlerin temel amacı bilgi alışverişinin sağlanmasıdır. Tüketicilerin çevrimiçi sunulan marka veya işletmenin paylaşımlarını takip etmesi onların satın alma olasılığının ölçülmesini de sağlamaktadır. Çevrimiçi bilgiler edinme, bilgi paylaşımı ve ürünü satın alma çevrimiçi satın alma niyetini ortaya çıkarmaktadır. Satın alma niyeti tüketicinin alışverişlerinde tekrar aynı markayı satın alması yönündeki vaatleridir. Tekrar satın alma davranı̧̧ı ise davranışsal açıdan marka sadakatinin bir belirleyicisidir.

Literatürde sosyal ağ pazarlaması, tüketici katılımı, satın alma niyeti ve marka sadakati değişkenleri ve bunlar arasındaki ilişkileri inceleyen birçok çalışma mevcuttur. Bu çalışmada ise farklı olarak ayrı ayrı incelenen bu değişkenlerin tek bir modelde test edilmesidir. Çalışmada öncelikle kavramsal çerçeve başlı̆̆ı altında değişkenler ele alınmış daha sonra bu değişkenler arasındaki ilişkiler açıklanarak hipotezler oluşturulmuştur. Daha sonra uygulanan anket çalışmasından elde edilen veriler Yapısal Eşitlik Modeli ile test edilmiştir. Elde edilen sonuçlara göre ise araştırmacı ve uygulamacılara çeşitli öneriler sunulmuştur.

\section{Literatür taramas1}

\section{Sosyal medya, sosyal ağlar ve pazarlama}

Dünyada meydana gelen teknolojik devrimin bir sonucu olarak hayatımıza giren bir kavram olan sosyal medya içerik, fikir, bakış açısı ve medya paylaşımları yapılabilen çevrimiçi araçlar olarak tanımlanmaktadır (Santosa,2020:1). Bir başka tanımda sosyal medya internet kullanıcılarının çevrim içi iletişim kurmalarına olanak sağlayan, içerik paylaşımı ve kişisel yorumlar gibi aktivitelere dayalı sosyal ağ siteleri olarak ifade edilmektedir (Kirtiş ve Karahan, 2011:262). Sosyal ağlar da sosyal medyadaki bloglar, vloglar, mesaj panoları, podcastler, wikiler gibi çevrimiçi kaynaklar arasında yer almaktadır (Drury, 2008:274). Kullanıcılarına kendi profillerini oluşturup bilgi paylaşmalarına ve diğer kullanıcılar ile iletişim kurmalarına olanak sağlayan sosyal ağlar insanların hayatlarında önemli bir yer edinmiş ve bu tür sitelere yönelik eğilimler artmaya başlamıştır. İşletmeler de markalarını pazarlamak için bu ortamlara yönelmişlerdir. Ürünleri farklı araçlar kullanarak pazarlamaya olanak sağlayan sosyal ağlar müşteri-işletme arasındaki etkileşimi de güçlendirmeye yardımcı olmaktadır (Ahmed ve Zahid, 2014:534). Sosyal medyanın iş ve özel hayat için sunduğu kolaylıklar, tüm dünyayı ilgilendiren haber ve bilgilere ulaşabilme, sosyalleşme, yeni iş fırsatları yakalama ve yeni stratejiler geliştirmeye yönelik katkıları işletmelerin müşterilerle iletişim ve iş adımlarının yapııış şekillerini de değiştirmiştir (Santosa, 2020:1; Toor vd., 2017: 173). Mevcut müşterilerle iletişime geçmek, müşteriye güven vermek, yeni müşteriler kazanmak, marka bilinirliğini ve imajını korumak adına işletmeler sosyal medya araçlarını kullanmaya başlamışlardır. Geleneksel pazarlama araçlarına göre daha düşük maliyetli olması ve daha büyük kitlelere zaman kısıtlaması olmadan ulaşmayı sağlaması sosyal medya araçlarını popüler hale getirmiştir (Koçak, Tümer Kabadayı ve Erişke, 2018: 497).

\section{Tüketici katılımı}

İlişkisel pazarlamanın daha geniş kapsamlı hali olarak literatürde yerini alan tüketici katılımı kavramı, tüketicilerin, marka veya işletmenin kısacası tarafların merkezileşmesini ve deneyimlerini paylaşma davranışlarını açıklamaktadır (Buran ve Koçak, 2019:278). Bu kavram, yalnızca alıcı-satıcı arasında kurulan ilişkileri değil mevcut ve potansiyel tüketiciler ile diğer tüm paydaşlar arasındaki katılımı da içermektedir (Farook ve Abeysekara, 2016: 116). Literatürde tüketici katılımı ile ilgili farklı yazarlar tarafından çeşitli tanımlar yapılmıştır. Patterson, Yu ve Ruyter (2006) tüketici katılımını, müşterinin bir marka veya işletme ile ilişkilerindeki davranışsal, bilişsel ve duygusal varlığının düzeyi şeklinde tanımlamıştır. Hollebeek (2011) benzer şekilde tüketici katılımını marka etkileşimlerindeki bilişsel, duygusal ve davranışsal faaliyetlerin seviyeleri ile belirlenen, güdüsel, markaya ilişkin ve içeriğe bağlı ruh hali seviyesi şeklinde ifade etmiştir. Doorn vd., (2010) tüketici katılımını basit işlemlerin ötesine geçen ve özel olarak motive edici itici güçlerden kaynaklanan, satın almanın ötesinde, marka odaklı bir müşteri davranışı olarak tanımlarken Vivek, Beatty ve Morgan (2012) bu 
kavramı bir müşteri ya da kuruluşun başlattığı ve bir kuruluşun sunumlarına veya kuruluşun faaliyetlerine bir bireyin katılım yoğunluğu şeklinde ifade etmişlerdir.

Tüketici katılımının temel unsuru bilgi alışverişidir. Bilgi ve iletişim teknolojilerinin gelişmesi ile tüketicilerin işletmelerle bilgi alışverişinde bulunması katılım sağlamaları açısından önem taşımaktadır (Farook ve Abeysekara, 2016: 116). Sosyal medya platformları gibi yeni teknolojiler de uzun vadeli müşteri ilişkilerine odaklanan stratejilerin benimsenmesini ve tüketici katılımı ile değer yaratan etkileşimlerin kullanımını artırmıştır (Başkol, 2019: 905). Tüketici katılımı, hem çevrimiçi marka etkinliklerine daha fazla katılım sağlayan davranışsal hem de marka gönderilerini "beğenme", "yorum yapma" veya kullanıcı tarafından içerik oluşturma gibi bilişsel faaliyetleri içermektedir (Tafesse, 2016: 425).

\section{Satın alma niyeti}

Satın alma niyeti tüketicinin gelecekte bir mal veya hizmeti satın alma olasılığı olarak tanımlanmaktadir (Kim ve Ko, 2012: 167; Alnsour, Ghannam, Al-Natour ve Alzeidat, 2018: 4). Dolayısıyla bu kavram sergilenecek satın alma davranışının temelini oluşturmaktadır (Ceyhan, 2019: 91). Satın alma niyeti mal veya hizmeti satın alma olasılığının ölçülmesini sağladığ iç̧in tüketici davranışlarını değerlendirebilmek açısından da çok önemlidir (Toor vd., 2017: 175). Çevrimiçi satın alma niyeti ise tüketicinin çevrimiçi işlemlere yönelik istekli ve dahil olma niyetinde olması durumudur. Bu çevrimiçi işlemler bilgi edinme, bilgi paylaşımı ve ürünü satın alma faaliyeti olarak kabul edilmektedir (Özçifçi, 2020: 209).

İşletmelerin markaları adına sosyal ağ sitelerinde yürüttükleri çevrimiçi pazarlama faaliyetleri, tüketicilerin satın alma niyetlerini etkilemede önemli bir faktör olarak kabul edilmektedir. Sosyal medya hesabında yapılan paylaşımlar tüketicilerin ilgisini çekebilir, mal veya hizmeti gözden geçirme isteği oluşturabilir ve sonuç olarak satın alma niyetlerini olumlu yönde etkileyebilir. Sosyal medya platformları tüketicileri satın alma niyetine ve davranışına duygusal olarak motive etmede etkili bir kaynaktır. Ayrıca sosyal medyanın sağladığı fonksiyonel, parasal, hedonik, psikolojik ve sosyal faydalar tüketicilerin satın alma niyetleri üzerinde önemli bir etki oluşturmaktadır. Dolayısıyla işletmelerin sosyal medyanın satın alma niyeti üzerindeki etkilerini belirleyerek buna yönelik pazarlama stratejiler geliştirmeleri gerekmektedir (Alnsour vd., 2018: 5).

\section{Marka sadakati}

Marka sadakatinin literatürde yapılan tanımlarında davranışsal ve tutumsal bileşenden oluşan bir kavram olarak ele alındığı görülmektedir. Davranışsal boyut tüketicinin belli bir markaya yönelik tekrarlı satın alma eğilimini ifade ederken tutumsal boyut tüketicinin toplam memnuniyetini anlatmaktadır (Liu vd., 2012: 924). Dolayısıyla marka sadakati bir veya daha fazla markaya yönelik bir müşterinin tekrar satın alma davranışıyla sonuçlanan olumlu tutumu olarak tanımlanmaktadır (Anderson ve Srininivasan, 2003 :125). Bir başka ifadeyle marka sadakati, müşterinin belirli bir markaya yönelik bağlılık derecesini ifade etmektedir (Leckie, Nyadzayo ve Johnson, 2016: 563).

Gelişen teknolojiyle beraber işletmeler, marka sadakati oluşturmaya yönelik faaliyetlerini sosyal medyaya taşımışlardır. Sosyal medya platformlarında oluşturulan marka topluluklarıyla tüketicilerin markanın pazarlama faaliyetlerine katılımı ve tüketicilerle doğrudan etkileşim kurulması sağlanmaktadır. Pazarlama faaliyetlerine katılımı yüksek olan tüketicilerin yeni ürün ve hizmet geliştirmeye aktif olarak katılmaları, fiyata karşı daha az duyarlı olmaları, marka değişimine direnç göstermeleri, olumlu ağızdan ağıza iletişimle markayı savunmaları ve geri bildirime açık olmaları gibi avantajlar marka sadakati yaratma noktasında tüketici katılımını daha önemli hale getirmiştir (Dwivedi, 2015: 103; Rather vd., 2018: 323; France, Merrilees ve Miller, 2016: 127).

\section{Hipotezler ve araştırmanın modeli}

\section{Sosyal ağ pazarlaması ve satın alma niyeti arasındaki ilişki}

Artık daha bilinçli ve ürünlerle ilgili daha çok bilgi arayışında olan tüketicilerin yer aldığı bir pazarda başarılı olabilmek için işletmelerin başvurduğu yeni platformlardan birisi de sosyal medyadır (Toor vd., 2017: 176). İşletmeler sosyal ağ siteleri aracilığıyla yürüttükleri pazarlama faaliyetleri ile tüketicilerin aradığı bilgiye kolayca ve hızlı bir şekilde ulaşmasını sağlamaktadırlar. Buna ek olarak sosyal ağlardaki pazarlama faaliyetleri tüketicilerin ürün tercihlerini ve satın alma niyetlerini de önemli ölçüde etkilemektedir (Ahmed ve Zahid, 2014: 534). Sosyal ağlar sayesinde işletmeler tüketicileri izleyerek düşüncelerine ve tercihlerine yön veren etmenleri belirlemekte bu sayede tercihlerini yönlendirmeye çalışmaktadırlar (Kara ve Coşkun, 2012: 74). 
Literatürde farklı ülkelerde, farklı örneklem grupları ve ürünler üzerinde yapılan çalışmalarda sosyal ağ sitelerindeki pazarlama faaliyetlerinin tüketicilerin satın alma niyetini pozitif yönde etkilediği tespit edilmiştir (Kim ve Ko, 2012; Balakrishnan, Dahnil ve Yi, 2014; Pjero ve Kercini, 2015; Gautam ve Sharmab, 2017; Sheth ve Kim, 2017; Almohaimmeed, 2019). Bu çalışmalarda elde edilen sonuçlardan yola çıkarak " $\mathrm{H}_{1}$ : Sosyal ağ pazarlaması tüketici satın alma niyetini pozitif yönde etkiler." hipotezi geliştirilmiştir.

\section{Sosyal ağ pazarlaması ve tüketici katılımı arasındaki ilişki}

Bundan birkaç yıl öncesine kadar ürünleri pazarlarken temas noktalarına vurgu yapıp tüketicilerin dikkatini çekmeye odaklanan bir kavram olarak kullanılan "tüketici katılımı" (Toor, vd., 2017:177) bugün tüketicilerle etkileşim kurarak onların katılımına odaklanan, satın alma davranışının ötesinde işletme-tüketici arasında duygusal bağ oluşturmakla ilgili bir kavram haline gelmiştir (Farook ve Abeysekara, 2016: 116). Bu bağı kurmak için işletmelerin önemini kabul ettikleri araçlardan biri de sosyal medya platformlarıdır (Ahmed ve Zahid, 2014: 308). İşletmeler sosyal medya pazarlamasını sadece ürünlerini tanıtmak amacıyla değil tüketicilerin katılımını sağlamak için de sıkça kullanmaktadırlar (Toor vd., 2017: 177). Sosyal ağ pazarlamasıyla tüketici katılımının sağlanması işletme ile tüketici arasında hızlı ve iki yönlü doğrudan bir iletişim kurulmasını, buna ek olarak taraflar arasında güven, iyi niyet ve bağlılığın gelişmesini sağlamaktadır (Muchardie, Yudiana ve Gunawan, 2016: 83; Farook ve Abeysekara, 2016: 115).

Literatürde farklı sosyal ağlar, farklı tüketici grupları ve farklı ürün grupları temelinde yapılan birçok araştırmada sosyal ağ pazarlamasının tüketici katılımını pozitif yönde etkilediği tespit edilmiştir (Muchardie, vd., 2016; Farook ve Abeysekara, 2016; Tafesse, 2016; Orel ve Arık, 2020; Liua, Shinb ve Burn, 2021). Yapılan çalışmalardan yola çıkarak " $\mathrm{H}_{2}$ : Sosyal ağ pazarlaması tüketici katılımını pozitif yönde etkiler." hipotezi geliştirilmiştir.

\section{Tüketici katılımı ve satın alma niyeti arasındaki ilişki}

Sosyal ağ pazarlama faaliyetleriyle tüketicilerin zihninde işletme veya marka ile ilgili oluşturulan konum işletme tarafından sunulan ürünleri satın alma konusunda tüketicilerin ikna olmasına yardımcı olmaktadır. Tüketicilerin bu anlamdaki katılım sürecinin etkin ve profesyonel bir şekilde yönetilmesi, satın alma niyetini de olumlu yönde etkilemektedir (Barhemmati ve Ahmad, 2015: 308). Magento (2015) 'e göre katılımları yüksek olan tüketicilerin her bir satın alma işlemine daha fazla harcama yaptıkları ve ürünleri daha sık satın almalarından dolayı işletmelere $\% 23$ daha fazla kar getirmektedir. Bu durum tüketicilerin yaşam boyu değerini artırmakta ve yeni müşteriler kazanma harcamalarını da azaltmaktadır. Katılımı yüksek olan tüketiciler çevrelerindeki kişileri tüketici olmaya ikna ederek maliyetleri azaltmaktadırlar (Toor vd., 2017:178).

Literatürde farklı ülkeler, farklı tüketici grupları, farklı sosyal ağlar ve ürünler üzerinde yapılan çalışmalarda tüketicilerin sosyal ağ pazarlamasına katılımları ile satın alma niyetleri arasında pozitif ilişki olduğu tespit edilmiştir (Barhemmati ve Ahmad, 2015; Toor vd., 2017; Kırcova, Yaman ve Köse, 2018; Prentice, Han, Hua ve $\mathrm{Hu}, 2019)$. Bu çalışmalardan yola çıkarak “ $\mathrm{H}_{3}$ : Tüketici katılımı tüketici satın alma niyetini pozitif yönde etkiler." hipotezi geliştirilmiştir.

\section{Tüketici katılımı ve marka sadakati arasındaki ilişki}

Marka yönetimi için önemli bir role sahip olan tüketici katılımı işletmelerin duygusal olarak sadık bir müşteri kitlesi oluşturmasına yardımcı olmaktadır (Fernandes ve Moreira, 2018: 275). Sadakat, durumsal etkilere ve pazarlama çabalarına bağlı olarak, tüketicilerin tercih edilen bir ürünü veya hizmeti gelecekte tutarlı bir şekilde yeniden satın almak veya kullanmak konusundaki derin bağllık olarak tanımlanmaktadır (Oliver, 1999: 34). Tanımda geçen "derin bağlllık" ifadesi tüketici-marka ilişkileri bağlamında sadakatin, yalnızca tekrarlanan satın almaları değil aynı zamanda markaya karşı olumlu içsel eğilimleri de kapsadığını belirtmektedir. Dolayısıyla tüketici marka katılımı, markaya karşı olumlu tutumlar oluşturması nedeniyle, tüketicileri satın almanın ötesinde etkileşimli marka deneyimleri ve kalıcı bir psikolojik bağlantı yoluyla daha sadık bir hale getirmektedir (Fernandes ve Moreira, 2018: 275). Literatürde bu ilişkiyi incelemek amacıyla farklı sektörlerde, farklı sosyal ağlar temelinde farklı örneklemler üzerinde birçok araştırma yapılmış ve sonuç olarak tüketici katılımının marka sadakatini pozitif yönde etkilediği tespit edilmiştir (So, King, Sparks ve Wang, 2014; Dwivedi, 2015; France, Merrilees ve Miller, 2016; Muchardie, Yudiana ve Gunawan, 2016; Lujja ve Özata, 2017; Rather, Tehseen ve Parrey, 2018; Islam, Rahman ve Hollebeek, 2018; Kaur, Paruthi, Islam ve Hollebek, 2020; Ting, Abbasi ve Ahmed, 2020). Bu çalışmalardan yola çıarak " $\mathrm{H}_{4}$ : Tüketici katılımı marka sadakatini pozitif yönde etkiler." hipotezi geliştirilmiştir. 


\section{Marka sadakati ve tüketici satın alma niyeti arasındaki ilişki}

Tüketici satın alma davranışını anlamak isteyen işletmeler için marka bağlılığındaki hızlı değişimle beraber satın alma niyetini etkileyen unsurları incelemek büyük önem taşımaktadır (Pandey ve Srivastava, 2016: 55). Satın alma niyeti bir kişinin bir ürünü ne zaman alışveriş için çıkarsa çıksın tekrar satın alması yönündeki vaatlerini ifade etmektedir (Fandos ve Flavian, 2006). Tekrarlanan satın alma davranışı ise davranışsal düzeyde incelendiği zaman sadakatin objektif bir belirleyicisi olarak görülmektedir (Oyman, 2002: 171). Literatürde farklı sektörlerde farklı ürünlere yönelik yapılan çalışmalar incelendiğinde markaya yönelik sadakat ile satın alma niyeti arasında pozitif bir ilişki olduğu tespit edilmiştir (Baldinger ve Rubinson, 1996; Chi, Yeh ve Yang, 2009, Jalilvandı, Samiei ve Mahdavinia, 2011; Porral ve Lang, 2015; Pandey ve Srivastava, 2016; Kim ve Lee, 2017; Laksama, 2018; Almohaimmeed, 2019; Panda vd., 2020). Bu sonuçlardan yola çıkarak “ $\mathrm{H}_{5}$ : Marka sadakati tüketici satın alma niyetini pozitif yönde etkiler." hipotezi geliştirilmiştir.

Araştırmanın modeli şekil 1'de gösterilmekte olup 4 değişkenden oluşmaktadır.

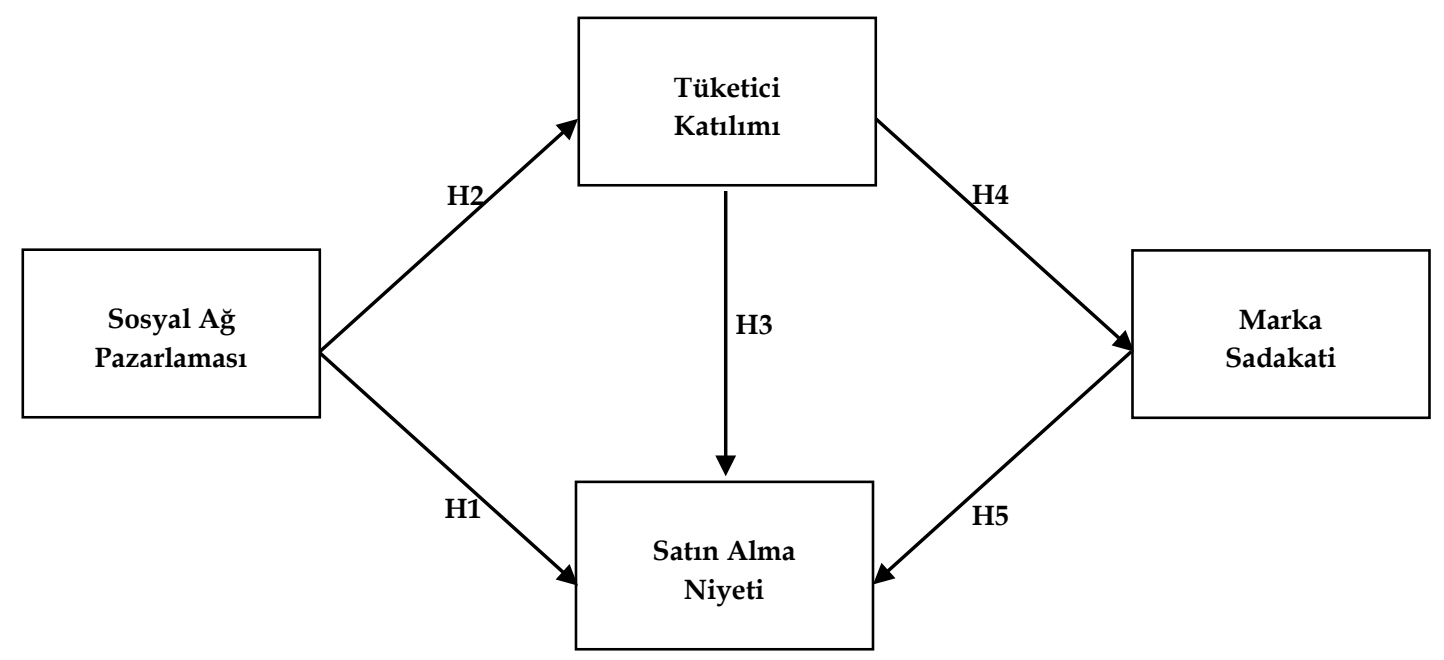

Şekil 1: Araştırmanın Modeli

Kaynak: Yazar tarafından üretilmiştir.

\section{Metodoloji}

\section{Veri toplama yöntemi ve ölçekler}

Araştırmanın ana kütlesini Ankara'da yaşayan 18 yaş ve üzeri sosyal medyayı kullanan tüketiciler oluşturmaktadır. Veriler online olarak sosyal ağlar aracılı̆̆ıyla toplanmıştır. Örnekleme yöntemi olarak ise kolayda örnekleme yöntemi kullanılmıştır. 600 kişiye anket uygulanmış, yanlış ve eksik doldurulan anketler elenmiş, toplam 577 anket değerlendirmeye alınmıştır. Araştırmada yer alan değişkenler ve değişkenleri oluşturmak için kullanılan kaynaklar Tablo 1'de sunulmuştur. Elde edilen anketlerin analizinde SPSS 20 ve LISREL 8.7 paket istatistik programları kullanılmıştır. Araştırmada tanımlayıcı istatistikler ve path analizi kullanılmıştır.

Tablo 1: Araştırmanın Değişkenleri

\begin{tabular}{ll}
\hline \multicolumn{1}{c}{ Değişkenler } & Yararlanılan Kaynaklar \\
\hline Sosyal Ağ Pazarlaması & Kim ve Ko (2012), Ahmed ve Zahid (2014) \\
Tüketici Katılımı & Weman (2011), Gummerus vd. (2012) \\
Satın Alma Niyeti & McKnight veChervany (2002), Wang ve Chang(2013), Yoo ve Donthu (2001) \\
Marka Sadakati & De Vries ve Carlson (2014), Zeithaml, Berry ve Parasuraman (1996) \\
\hline
\end{tabular}

\section{Verilerin analizi}

\section{Cevaplayıcıların demografik ve ekonomik özellikleri}

Katılımcıların \%60,5'ini kadın, \%39,5'ini erkekler oluşturmaktadır. Örneklemin çoğunluğunu yüksek eğitimli ve gelir seviyesi yüksek tüketiciler oluşturmaktadır. Katılımcıların \%39,9'u sosyal medyayı günde çok sık ziyaret etmekte ve genellikle zaman geçirmek için sosyal medyayı kullanmaktadır. En 
çok kullandıkları sosyal ağ ise İnstagram olarak belirlenmiştir. Araştırma kapsamındaki örnekleme ilişkin bilgiler Tablo 2' de sunulmuştur.

Tablo 2: Demografik Özellikler ve Sosyal Medya Kullanım Davranışları

\begin{tabular}{|c|c|c|c|c|c|}
\hline Cinsiyet & f & $\%$ & Sosyal Ağlardan Alışveriş Yapma & f & $\%$ \\
\hline Kadın & 349 & 60,5 & Evet & 467 & 80,9 \\
\hline Erkek & 228 & 39,5 & Hayır & 105 & 18,2 \\
\hline En çok kullanılan Sosyal A $\breve{g}$ & f & $\%$ & Sosyal Ă̆ Kullanım Amacı & f & $\%$ \\
\hline Facebook & 30 & 5,2 & Fotoğraf yüklemek/ bakmak & 30 & 5,2 \\
\hline İnstagram & 242 & 41,9 & Sosyal gruplardan haberdar olmak & 67 & 11,6 \\
\hline Twitter & 63 & 10,9 & Arkadaşlık ilişkilerini sürdürmek & 60 & 10,4 \\
\hline Youtube & 34 & 5,9 & Zaman geçirmek & 191 & 33,1 \\
\hline Whatsapp & 197 & 34,1 & İnsanlara kolay erişmek & 43 & 7,5 \\
\hline Messenger & 2 & 0,3 & Profil okumak & 6 & 1,0 \\
\hline Pinterest & 1 & 0,2 & Yeni arkadaşlar edinmek & 132 & 22,9 \\
\hline Linked in & 5 & 0,9 & Alışveriş yapmak & 39 & 6,8 \\
\hline Tiktok & 3 & 0,5 & Sayfaların gönderilerine bakmak & 9 & 1,6 \\
\hline Takip Edilen Ürün Grubu & $\mathrm{f}$ & $\%$ & S.A kullanım Süresi & f & $\%$ \\
\hline Kiyafet & 207 & 35,9 & 2 saatten az & 245 & 42,5 \\
\hline Kozmetik & 29 & 5,0 & $2-5$ saat arası & 280 & 48,5 \\
\hline Teknoloji & 132 & 22,9 & 5 saatten fazla & 52 & 9,0 \\
\hline Mobilya & 20 & 3,5 & S.A Ziyaret Sıklığı & $\mathrm{f}$ & $\%$ \\
\hline Mutfak eşyaları & 17 & 2,9 & $1-5 \mathrm{kez}$ & 130 & 22,5 \\
\hline Tak1/Aksesuar & 16 & 2,8 & $6-10 \mathrm{kez}$ & 217 & 37,6 \\
\hline Spor malzemeleri & 38 & 6,6 & $11 \mathrm{kez}+$ & 230 & 39,9 \\
\hline Anne-bebek ürünleri & 17 & 2,9 & & & \\
\hline El emeği ürünler & 29 & 5,0 & & & \\
\hline Ayakkabı/çanta & 11 & 1,9 & & & \\
\hline Gida & 55 & 9,5 & Toplam & 577 & 100 \\
\hline
\end{tabular}

\section{Ölçeklerin güvenirlik ve geçerliliğinin test edilmesi}

Modelde yer alan hipotezleri test etmeden önce değişkenlere ait ölçeklerin güvenirlilik ve geçerlilik analizleri yapılmıştır. Ölçeklerin güvenilirliklerini test etmek amacıyla Cronbach alfa değerleri hesaplanmış ve bu değerler Tablo 3'te gösterilmiştir. Ölçeklerinin Cronbach Alfa değerlerinin, 70'in (Nunnally, 1978: 245) üzerinde olması ölçeklerin güvenilir olduğunu göstermektedir.

Yapı geçerliliğinin sağlanabilmesi için yakınsama ve ayrım geçerliliğinin beraber sağlanması gerekmektedir. Yakınsama geçerliliğini test etmek için ölçüm modeline ait boyutların açıklanan ortalama varyans (AVE) değerleri ve birleşik güvenilirlik katsayıları (CR) hesaplanmış ve Tablo 3'te gösterilmiştir. Ölçeklerin önerilen birleşik güvenirlik (CR) katsayıları ,70, açılanan ortalama varyans değerleri de (AVE) ,50'nin (Hair vd., 2010) üzerinde olduğu ve ölçeklerin yakınsama geçerliliğine sahip olduğu belirlenmiştir.

Ölçeklerin ayrım geçerliliğini sağlayıp sağlayamadığını test etmek amacıyla her bir değişkenin açıkladığı ortalama varyansın karekökü ile değişkenler arası korelasyon değerleri karşılaştırılmıştır. Bir boyut için ortalama artık varyansın kare kökü, bu boyut ile diğer boyutlar arasındaki korelasyonun karesinden daha büyük olmalıdır (Cooper ve Zmud, 1990). Tablo 3'e göre, köşedeki değerler her bir boyut için varyansın ortalama karesini gösterirken, köşegenin dışındaki değerler, boyutların diğer boyutla korelasyon değerlerinin karesini göstermektedir. Ortalama artık varyansın karekökü korelasyonların karesinden büyük elde edilmiştir ve bu durumda ayrım geçerliliği sağlanmıştır.

Tablo 3: Modelin Cronbach Alfa Değeri, Yakınsama ve Ayrım Geçerliliği

\begin{tabular}{|c|c|c|c|c|c|c|c|}
\hline & $\mathbf{a}$ & CR & AVE & TK & SAN & MS & SA \\
\hline Tüketici Katılımı & $85^{0}$ & 0.913 & 0.639 & 0.799 & & & \\
\hline Satın Alma Niyeti & $\begin{array}{c}.885 \\
0 \\
.860\end{array}$ & 0.905 & 0.705 & 0.724 & 0.840 & & \\
\hline Marka Sadakati & $.916^{0}$ & 0.935 & 0.705 & 0.726 & 0.722 & 0.840 & \\
\hline Sosyal A $\breve{g}$ & $.881^{0}$ & 0.909 & 0.591 & 0.713 & 0.729 & 0.655 & 0.769 \\
\hline
\end{tabular}

\section{Araştırma modelinin testi}

Modeli test etmek için Yapısal Eşitlik Modeli (path analizi) kullanılmıştır. Path analizinde, sosyal ağ pazarlamasının tüketici katılımı ve satın alma niyetine; tüketici katılımının satın alma niyeti ve marka 
sadakatine ve satın alma niyetinin marka sadakatine etkisi belirlenmeye çalışılmıştır. Yapılan ilk analiz sonucunda, uyum değerlerinin istatistiki bakımdan kabul edilebilir düzeyde olmadığı görülmüştür. Bu analizin uyum değerleri Tablo 4'te gösterilmiştir.

Tablo 4: Modelin Modifikasyon Öncesi Uyumluluk İndeks Değerleri

\begin{tabular}{lcc}
\hline Uyumluluk İndeksi & Indeks Değeri & Kabul Edilebilir Uyum \\
\hline Ki-Kare $\left(\mathrm{X}^{2}\right)$ & 1654.41 & \\
Serbestlik Derecesi(sd) & 226 & \\
Ki-Kare/sd & 7.32 & $1-5$ \\
P-value & 0.000 & \\
GFI & 0.80 & $0.90 \leq \mathrm{GFI} \leq 0.95$ \\
AGFI & 0.75 & $0.85 \leq \mathrm{AGFI} \leq 0.90$ \\
RMSEA & 0.105 & $0.05 \leq \mathrm{RMSA} \leq 0.08$ \\
CFI & 0.96 & $0.95 \leq \mathrm{CFI} \leq 0.97$ \\
NNFI & 0.96 & $0.95 \leq \mathrm{NNFI} \leq 0.97$ \\
NFI & 0.96 & $0.95 \leq \mathrm{NFI} \leq 0.97$ \\
\hline
\end{tabular}

Sonuçlara göre; 1654.41 ki-kare değeri ve 226 serbestlik derecesinin birbirine oranı 7.32 olup, önerilen 5 değerinden büyük olması nedeniyle kabul edilebilir düzeyde değildir. Uyum indeksi (GFI)'nın değeri 0.80 olup, 0.90 'dan küçük olduğu için kabul edilebilir düzeyde değildir. Düzeltilmiş iyilik indeksi (AGFI) 0.75 olup, önerilen 0.85 'ten düşük olduğu için kabul edilebilir düzeyde değildir. RMSEA değeri 0.105 olup, istatistiki olarak önerilen 0.08 değerinden büyük olduğu için bu değer modelin kabul edilebilirliği için yeterli değildir. Bu değerlere göre, araştırma modeli kabul edilebilirlik için yeterli değildir.

Modifikasyonlar incelenerek Ki-Kare üzerinde en yüksek değerde modifikasyon öneren değişkenler analiz dışı bırakılmıştır. Yapılan modifikasyonlar sonrasında elde edilen indeks değerleri, kabul edilebilir değerler içerisinde yer almıştır. Modifikasyon sonrası model uyum indeks değerleri Tablo 5 'de gösterilmiştir.

Tablo 5: Modelin Modifikasyon Sonrası Uyumluluk İndeks Değerleri

\begin{tabular}{|c|c|c|}
\hline Uyumluluk İndeksi & İndeks Değeri & Kabul Edilebilir Uyum \\
\hline Ki-Kare $\left(\mathrm{X}^{2}\right)$ & 480.84 & \\
\hline Serbestlik Derecesi(sd) & 114 & \\
\hline Ki-Kare/sd & 4.2 & $1-5$ \\
\hline P-Value & 0.000 & \\
\hline GFI & 0.91 & $0.90 \leq \mathrm{GFI} \leq 0.95$ \\
\hline AGFI & 0.88 & $0.85 \leq \mathrm{AGFI} \leq 0.90$ \\
\hline RMSEA & 0.07 & $0.05 \leq$ RMSEA $\leq 0.08$ \\
\hline CFI & 0.98 & $0.95 \leq \mathrm{CFI} \leq 0.97$ \\
\hline NNFI & 0.98 & $0.95 \leq \mathrm{NNFI} \leq 0.97$ \\
\hline NFI & 0.97 & $0.95 \leq \mathrm{NFI} \leq 0.97$ \\
\hline
\end{tabular}

Modifikasyon sonrası uyum indeks değerlerinin kabul edilebilir düzeyde olduğu belirlenmiştir. Elde edilen uyum indeks değerleri yukarıdaki tabloda görülmektedir. Tabloya göre araştırma için oluşturulan modelin incelenen sektör ve saha açısından uygun olduğu ifade edilebilir.

Yapılan yapısal eşitlik modeli analizine göre, model için önerilen modifikasyonlar yapılmıştır. Modifikasyonlar doğrultusunda sosyal ağ pazarlama ölçeğinden 2, tüketici katılımı ölçeğinden 1, niyet ölçeğinden 1 ve marka sadakati ölçeğinde 2 ifade modelden çıkarılmıştır. Kalan değişkenler ve değişkenlerin $t$ değerleri, standart katsayılar, $R^{2}$ ve hata varyanslarına ait değerleri Tablo $6^{\prime}$ da gösterilmiştir. 
Tablo 6: Araştırma Modelinin t Değerleri, Standart Katsayılar, $R^{2}$ ve Hata Varyansları

\begin{tabular}{|c|c|c|c|c|}
\hline Değişkenler & $\begin{array}{c}\mathbf{t} \\
\text { Değerleri } \\
\end{array}$ & $\begin{array}{c}\text { Standart } \\
\text { katsayılar }\end{array}$ & $\mathbf{R}^{2}$ & Hata varyans1 \\
\hline $\begin{array}{l}\text { S1 Takip ettiğim markalar ile ilgili bilgimi artırmak için sosyal ağları } \\
\text { kullanmayı seviyorum. }\end{array}$ & 21.35 & 0.78 & 0.61 & 0.46 \\
\hline $\begin{array}{l}\text { S2Takip ettiğim markaların sosyal ağlardaki pazarlama faaliyetlerinden } \\
\text { memnunum. }\end{array}$ & 22.23 & 0.80 & 0.64 & 0.32 \\
\hline $\begin{array}{l}\text { S3 Takip ettiğim markaların sosyal ağlardaki pazarlama faaliyetlerinin } \\
\text { çekici olduğunu düşünüyorum. }\end{array}$ & 21.15 & 0.77 & 0.6 & 0.38 \\
\hline $\begin{array}{l}\text { S4 Takip ettiğim markanın sosyal ağlardaki hesaplarını incelemek } \\
\text { eğlencelidir. }\end{array}$ & 22.32 & 0.80 & 0.64 & 0.36 \\
\hline $\begin{array}{l}\text { S7 Takip ettiğim markanın sosyal ağlardaki hesapları fikirlerimi iletmemi } \\
\text { kolaylaştırır. }\end{array}$ & 14.61 & 0.58 & 0.34 & 0.71 \\
\hline $\begin{array}{l}\text { K1 Takip ettiğim markaların sosyal ağlardaki sayfalarını sık sık ziyaret } \\
\text { ederim. }\end{array}$ & 12.93 & 0.82 & 0.68 & 0.34 \\
\hline $\begin{array}{l}\text { K3 Takip ettiğim markaların sosyal ağlardaki gönderilerini çoğu zaman } \\
\text { beğenirim. }\end{array}$ & 17.25 & 0.67 & 0.45 & 0.62 \\
\hline $\begin{array}{l}\text { K4 Takip ettiğim markaların sosyal ağlardaki sayfalarına sık sık yorum } \\
\text { yaparım. }\end{array}$ & 14.16 & 0.57 & 0.33 & 0.60 \\
\hline $\begin{array}{l}\text { K5 Takip ettiğim marka ile ilgili yenilikleri takip etmek için sosyal } \\
\text { ağlardaki sayfalarını sık sık incelerim. }\end{array}$ & 23.77 & 0.86 & 0.73 & 0.32 \\
\hline $\begin{array}{l}\text { K6 Sosyal ağlarda takip ettiğim markanın bir parçası olmak onlara olan } \\
\text { güvenimi artırır. }\end{array}$ & 19.15 & 0.73 & 0.53 & 0.54 \\
\hline $\begin{array}{l}\text { N2 Markanın sosyal ağlardaki sayfalarını takip etmek ürün satın alma } \\
\text { konusundaki ilgimi artırıyor. }\end{array}$ & 13.71 & 0.79 & 0.62 & 0.40 \\
\hline $\begin{array}{l}\text { N3 Sosyal ağ sitelerinde arkadaşlarım tarafından önerilen ürün satın alma } \\
\text { ihtimalim çok yüksektir. }\end{array}$ & 18.45 & 0.74 & 0.55 & 0.55 \\
\hline $\begin{array}{l}\text { N4 Takip ettiğim markanın sosyal ağ sitelerinde pazarlanan ürün satın } \\
\text { alma ihtimalim yüksektir. }\end{array}$ & 21.28 & 0.84 & 0.70 & 0.31 \\
\hline SD1Sosyal ağ sitesinde takip ettiğim markayı başkalarına tavsiye ederim. & 11.96 & 0.85 & 0.72 & 0.29 \\
\hline SD2 Sosyal ağ sitesinde takip ettiğim markayı diğer insanlara tanıtırım. & 20.46 & 0.75 & 0.57 & 0.51 \\
\hline SD3 Başkalarına takip ettiğim marka hakkında olumlu şeyler söylerim. & 22.24 & 0.80 & 0.64 & 0.36 \\
\hline SD4 Gelecekte takip ettiğim bu markaya sadık kalmayı planlıyorum. & 19.87 & 0.74 & 0.54 & 0.44 \\
\hline
\end{tabular}

S: Sosyal Ağ Pazarlaması N: Satın Alma Niyeti K: Tüketici Katılımı SD: Marka Sadakati

Araştırma modelinin modifikasyonlar sonrası oluşan path diyagramı Şekil 2' de gösterilmektedir. 


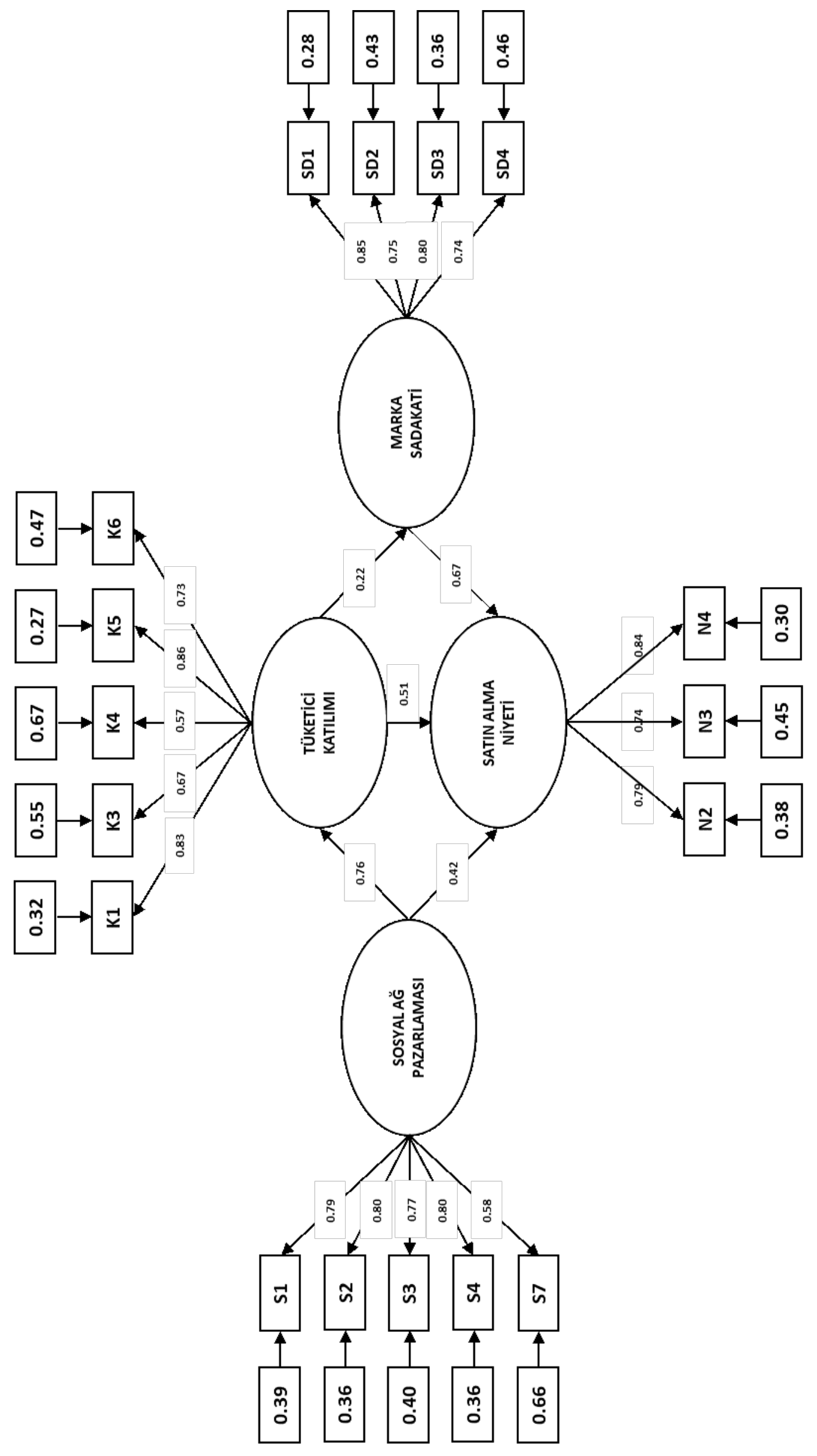

Şekil 2: Araştırma Modelinin Path Diyagramı 
Modifikasyon sonrası değişkenleri arasındaki standart katsayılar, $\mathrm{R}^{2}$, hata varyansları ve $\mathrm{t}$-değerleri Tablo 7'de gösterilmiştir.

Tablo 7: Faktörler Arasındaki İlişkiler

\begin{tabular}{lcccc}
\hline \multicolumn{1}{c}{ DEĞişKENLER } & $\begin{array}{c}\mathbf{t} \\
\text { değerleri }\end{array}$ & $\begin{array}{c}\text { Standart } \\
\text { katsayılar }\end{array}$ & $\mathbf{R}^{2}$ & Hata varyansı \\
Sosyal Ağ Pazarlaması- Tüketici Katılımı & 16.81 & 0.76 & 0.57 & 0.43 \\
Sosyal Ağ Pazarlaması-Satın Alma Niyeti & 0.42 & 0.42 & 0.77 & 0.23 \\
Tüketici Katılımı-Satın Alma Niyeti & 0.51 & 0.51 & 0.77 & 0.23 \\
Tüketici Katılımı-Marka Sadakati & 0.22 & 0.22 & 0.76 & 0.24 \\
Marka Sadakati-Satın Alma Niyeti & 0.67 & 0.67 & 0.76 & 0.24 \\
\hline
\end{tabular}

Sosyal ağ pazarlamasının tüketici katılımı $(\beta=0.76)$ ve satın alma niyeti üzerinde $(\beta=0.42)$ anlamlı ve pozitif etkisi bulunmaktadır. Dolayısıyla araştırmanın $\mathrm{H}_{1}$ ve $\mathrm{H}_{2}$ hipotezleri kabul edilmiştir. Tüketici katılıminın satın alma niyeti $(\beta=0.51)$ ve marka sadakati $(\beta=0.22)$ üzerinde anlamlı ve pozitif etkisi bulunmaktadır. $\mathrm{Bu}$ nedenle araştırmanın $\mathrm{H}_{3}$ ve $\mathrm{H}_{4}$ hipotezleri kabul edilmiştir. Son olarak marka sadakatinin satın alma niyeti $(\beta=0.67)$ üzerinde anlamlı ve pozitif etkisi bulunduğu tespit edilmiş ve araştırmanın $\mathrm{H}_{5}$ hipotezi kabul edilmiştir.

\section{Sonuç ve öneriler}

İşletmelerin müşterilerle iletişim kurmak, yeni müşteriler kazanmak, marka bilinirliğini sağlamak, imajı korumak vb. amaçlarla yürütülen sosyal ağ faaliyetleri online tüketici katılımını ve satın alma niyetini pozitif yönde etkilemektedir. Bu sonuç daha önce yapılan çalışmaları (Barhemmati ve Ahmad, 2015; Farook ve Abeysekara, 2016; Muchardie, vd., 2016; Kim ve Ko, 2010; Hutter ve diğerleri, 2013; Toor vd., 2017; Laksamana, 2018; Almohaimmeed, 2019) desteklemektedir. Markaların sosyal ağlardaki faaliyetleri tüketicilerin bu faaliyetlere bilişsel ve davranışsal katılımlarını etkilemektedir. Sosyal ağlarda tüketicilerin keyif alabilecekleri eğlenceli, ilgi çekici, fotoğraf veya video içerikli paylaşımlar yapmak, tüketicilerin beğenme, paylaşma ve yorum yapma şeklindeki katılımlarını artırmak için kullanılabilir. Özellikle en çok takip edilen ürün grubu olan kıyafet markalarının sayfalarında güncel içerikler sunması, paylaşımlarını güncel tutması ve paylaşım sürelerine dikkat etmesi gerekmektedir. Böylece tüketicilerin katılımları artırılarak marka ile daha fazla etkileşim kurması sağlanabilir. Markaların sosyal ağlardaki faaliyetleri benzer şekilde tüketicilerin çevrim içi işlemlere yönelik istekli olmasını ve bir ürünü satın alma olasılı̆̆ını da etkilemektedir. Özellikle tüketicilerin ürünü satın almasını sağlamak için ürün veya marka hakkındaki bilgilerini artıracak paylaşımlarda bulunmak etkili olabilir. Buna ek olarak tüketicinin kafasındaki soruları yanıtlamak adına sosyal ağlarda ürün özellikleri, yeni çıkan ürünler, promosyonlar veya diğer sunulan ek hizmetlerle ilgili ayrıntılı bilgi verebilirler. Satın alma sonrasında veya öncesindeki soru ve şikayetleri değerlendirmek ve hızlı dönüşler yapmak üzere bir sistem oluşturmak yine satın alma niyeti üzerinde pozitif bir etki yaratabilir. Tüketicilerin markaya güven duymasını sağlayabilir. Bu güveni sağlamak satın alma, ödeme, bilgi kaydı vb. konularda güvenlik tedbirleriyle desteklenebilir ve tüketiciler ürün satın almaya teşvik edilebilir.

Tüketicilerin çevrimiçi katılımı, satın alma niyeti ve marka sadakati arasında ilişkiler bulunmaktadır. Literatürde bu sonucu destekleyen çalışmalar da mevcuttur. (Prentice vd.,2019; Toor vd., 2017; Dwivedi, 2015; Solem, 2016; Islam, Rahman ve Hollebeek, 2017; Fernandes ve Moreira, 2018; Rather vd. 2018; Kaur vd., 2020; Ting, Abbasi ve Ahmed, 2020; Chi, Yeh ve Yang, 2009; Jalilvand vd., 2011; Porral ve Lang, 2015; Kima ve Lee,2017; Ceyhan, 2019). Tüketicilerin sosyal ağlarda vakit geçirmesi, paylaşımda bulunması, yorumlar yapması vb. hem kendileri için hem de diğer tüketicilerin markayı satın alma niyetlerini etkilemektedir. Bu niyetleri davranışa dönüştürmek için işletmeler ödüller, çekilişler, yarışmalar düzenleyerek katılımı sağlayabilir ve satın almaya yönelik ilgileri artırabilirler. Satın alma niyeti davranışa dönüştüğünde ve memnuniyet oluştuğunda ise tüketici o ürünü satın almaya devam etmekte ve bağlılık oluşmaktadır. Tüketicilerin sosyal ağlardaki faaliyetlere katılması onların markaya olan ilgilerini artırmakta ve aidiyet duygularını geliştirerek güçlü bir marka sadakati oluşturmaya yardımcı olmaktadır. Dolayısıyla tüketicilerin kendilerini markanın bir parçası olarak görmesi bağllıklarını artırabilir ve ağızdan ağıza iletişim yoluyla diğer tüketicileri etkilemesi sağlanabilir.

Araştırma Ankara ilinde ikamet eden 18 yaş ve üstü 600 tüketiciüzerine yapılmıştır. İleride daha geniş tüketici grupları ile benzer bir çalışmanın yapılmasında fayda vardır. Çalışmada sosyal ağ siteleri 
bütün olarak ele alınmıştır. Gelecekteki çalışmalarda farklı sosyal ağ platformlarında tüketici katılımlarının etkisi ayrı ayrı incelenebilir. Ayrıca gelecekteki çalışmalarda modele (tüketici katılımının boyutları, sosyal pazarlamanın boyutları gibi) değişkenler eklenerek incelenebilir.

\section{Hakem Değerlendirmesi / Peer-review:}

Dış bağımsız

Externallypeer-reviewed

\section{Çıkar Çatışması / Conflict of interests:}

Yazar(lar)çıkar çatışması bildirmemiştir.

Theauthor(s) has (have) noconflict of interesttodeclare.

\section{Finansal Destek / Grant Support:}

Yazar(lar) bu çalışma için finansal destek almadığını beyan etmiştir.

The author(s) declared that this study has received no financial support.

\section{Etik Kurul Onay1/ EthicsCommitteeApproval:}

Bu çalışma için etik kurul onayı, Ufuk Üniversitesi, Sosyal ve Beşerî Bilimler Bilimsel Araştırma ve Yayın Etiği Kurulundan 10/02/2021tarihli 2021/15 sayılı karar ile alınmıştır.

Ethicscommitteeapprovalwasreceivedforthisstudyfrom Ufuk University, Social and Human Sciences Scientific Research and Publication EthicsCommittee on 10/02/2021 and 2021/15 document number.

\section{Yazar Katkıları/ Author Contributions:}

Fikir/Kavram/Tasarım-Idea/Concept/ Design: L.G.Ö.,A.D.Ç.Veri Toplama ve/veya İşleme - Data Collection and/or Processing: L.G.Ö.,A.D.Ç.Analiz ve/veya Yorum - Analysis and/or Interpretation: L.G.Ö.,A.D.Ç. Kaynak Taraması - Literature Review: L.G.Ö.,A.D.Ç.Makalenin Yazımı - Writing the Article: L.G.Ö.,A.D.Ç.Eleştirel İnceleme - Critical Review: L.G.Ö.,A.D.Ç. Onay - Approval: L.G.Ö.,A.D.Ç.

\section{Kaynakça / References}

Ahmed, M. A., \& Zahid, Z. (2014). Role of Social Media Marketing to Enhance CRM and Brand Equity in Terms of Purchase Intention. Asian Journal of Management Research, 4 (3), 533-549.

Almohaimmeed, B. M.A. (2019). The Effects of Social Media Marketing Antecedents on Social Media Marketing, Brand Loyalty and Purchase Intention: A Customer Perspective. Journal of Business and Retail Management Research (JBRMR), 13 (4), 146-157.

Alnsour, M., Ghannam, M., Al-Natour, \& R., Alzeidat Y. (2018). Social Media Effect On Purchase Intention: Jordanian Airline Industry. Journal of Internet Banking and Commerce, June, 23(2), 1-16.

Anderson, R.E. \& Srinivasan, S.S. (2003). E-satisfaction and e-loyalty: A Contingency Framework. Psychology \& Marketing, 20(2), 123-138.

Balakrishnan B.K., Dahnil M.I., Yi W. J., (2014), “The Impact of Social Media Marketing Medium Toward Purchase Intention and Brand Loyalty Among Generation Y", ProcediaSocialandBehavioralScineces, Vol:148, 177-185.

Baldinger, A. L. \& Rubinson, J. (1996), Brand Loyalty: The Link Between Attitude and Behavior, Journal of Advertising Research, November/ December, 22-34.

Barhemmati, N., \&Ahmad, A. (2015). Effects of Social Network Marketing (SNM) on Consumer Purchase Behavior Through Customer Engagement. Journal of Advanced Management Science, 3(4), 307-311.

Başkol, M. (2019). Algılanan Değer, Müşteri Katılımı ve Algılanan Firma Performansı İlişkisi. Uluslararası Yönetim İktisat ve İşletme Dergisi, 15(3), 904-922.

Buran, İ., \& Koçak, A. (2019). Sanal Marka Topluluklarında Tüketici Katılımı. Pazarlama ve Pazarlama Araştırmaları Dergisi, Sayı: 24, Temmuz; 273-302. 
Ceyhan, A. (2019). The Impact of Perception Related Social Media Marketing Applications on Consumers' Brand Loyalty and Purchase Intention. Emerging Markets Journal, 9 (1), 87-100.

Chi, H., Yeh, H., \& Yang, Y. (2009). The Impact of Brand Awareness on Consumer Purchase Intention: The Mediating Effect of Perceived Quality and Brand Loyalty. The Journal of International Management Studies, 4 (1), 135-144.

Cooper, R. B., \&Zmud, R. W. (1990). Information Technology Implementation Research: A Technological Diffusion Approach. Management Science, 36 (2), 123-139.

De Vries, N. J., \&Carlson, J. (2014). Examining The Drivers and Brand Performance Implications of Customer Engagement With Brands in The Social Media Environment. Journal of Brand Management, 21 (6), 495-515.

Doorn, J.V.; Lemon, N. K., Mittal, V., Nass S., Pick, D., Pirner, P., \& Verhoef P., (2010). Customer Engagement Behavior: Theoretical Foundations and Research Directions. Journal of Service Research, 13 (3), 253-266.

Drury, G. (2008). Opinion piece: Social media: Should Marketers Engage and How Can It Be Done Effectively?. Journal of Direct, Data and Digital Marketing Practice, 9, 274-277.

Dwivedi, A. (2015). A Higher-Order Model of Consumer Brand Engagement And its Impact on Loyalty Intentions. Journal of Retailing and Consumer Services, Vol. 24; 100-109.

Fandos, C., \& Flavian, C. (2006). Intrinsic and Extrinsic Quality Attributes, Loyalty and Buying Intention: An Analysis For a PDO Product. British Food Journal, 108 (8), 646-662.

Farook, S.F., \& Abeysekara, N. (2016). Influence of Social Media Marketing on Customer Engagement. International Journal of Business and Management Invention, 5 (12), 115-125.

Fernandes, T., \& Moreira, M. (2018). Consumer Brand Engagement, Satisfaction And Brand Loyalty: A Comparative Study Between Functional And Emotional Brand Relationships. Journal of Product \& Brand Management, 28 (2), 274-286.

France, C., Merrilees, B., \& Miller, D., (2016). An Integrated Model of Customer- Brand Engagement; Drivers and Consequences. Journal of Brand Management, 23 (2), 119-136.

Gautam, V., \& Sharmab, V. (2017). The Mediating Role of Customer Relationship on the Social Media Marketing and Purchase Intention Relationship with Special Reference to Luxury Fashion Brands. Journal of Promotion Management, 23 (6), 872-888.

Gummerus, J., Liljander, V., Weman, E., \& Pihlström, M. (2012). Customer Engagement in A Facebook Brand Community. Management Research Review, 35 (9), 857-877.

Hair, J. F., Black, W. C., Babin, B. J., \& Anderson, R. E. (2010). Multivariate Data Analysis: A Global Perspective. New Jersey: Pearson Prentice Hall.

Hollebeek, L.D. (2011). Demystifying Customer Brand Engagement: Exploring The Loyalty Nexus. Journal of Marketing Management, 27 (7-8), 785-807.

Hutter, K., Hautz, J., Dennhardt, S., \&Fuller. J. (2013). The Impact of User Interactions in SOCIAL media on Brand Awareness and Purchase Intention: The Case of MINI on Facebook. Journal of Product \& Brand Management, 22, (5/6), 342 - 351.

Islam, J.U., Rahman, Z., \&Hollebeek, L.D. (2018). Consumer Engagement in Online Brand Communities: A Solicitation of Congruity Theory. Internet Research, 28 (1), 23-45.

Jalilvand1, M. R., Samiei, N., \& Mahdavinia, S.H. (2011). The Effect of Brand Equity Components on Purchase Intention: An Application of Aaker's Model in the Automobile Industry. International Business and Management, 2 (2), 149-158.

Kara, Y., \& Çoşkun, A. (2012). Sosyal Ağların Pazarlama Aracı Olarak Kullanımı: Türkiye'deki Hazır Giyim Firmaları Örneği. Afyon Kocatepe Üniversitesi iktisadi ve İdari Bilimler Fakültesi Dergisi, 14 (2), 73-90.

Kaur, H., Paruthi, M., Islam, J., \&Hollebek, L.D. (2020). The Role Of Brand Community Identification and Reward on Consumer Brand Engagement and Brand Loyalty in Virtual Brand Communities. Telematics and Informatics, 46, March, 101-121. 
Kırcova, İ., Yaman, Y., \& Köse, Ş.G. (2018). Instagram, Facebook or Twitter: Which Engages Best? A Comparative Study of Consumer Brand Engagement and Social Commerce Purchase Intention. European Journal of Economics and Business Studies, 4 (1), 268-278.

Kim, A. J., \& Ko, E. (2010). “Impacts of Luxury Fashion Brand's Social Media Marketing on Customer Relationship and Purchase Intention. Journal of Global Fashion Marketing, 1 (3), 164-171.

Kim, A.J., \&Ko, E. (2012). Impacts of Luxury FashionBrand's Social Media Marketing on Customer Relationship and Purchase Intention. Journal of Global Fashion Marketing, 1 (3), 164-171.

Kim, J., \& Lee, H. K. (2017). Influence of Integration on Interactivity in Social Media Luxury Brand Communities. Journal of Business Research, Vol:99, 422-429.

Kirtiş, K. A., \&Karahan, F. (2011). To Be or Not TO Be in Social Media Arena As The Most CostEfficient Marketing Strategy After The Global Recession., Procedia Social and Behavioral Sciences, Vol.24; 260-268.

Koçak, A., Tümer Kabadayı, E., \& Erişke T. (2018). İletişimin Yeni Yüzü: Dijital Pazarlama ve Sosyal Medya Pazarlaması. Elektronik Sosyal Bilimler Dergisi, 17 (66), 493-504.

Laksamana, P. (2018). Impact of Social Media Marketing on Purchase Intention and Brand Loyalty: Evidence from Indonesia's Banking Industry. International Review of Management and Marketing, 8 (1), 13-18.

Leckie, C., Nyadzayo, M.W., \& Johnson, L.W. (2016). Antecedents of Consumer Brand Engagement And Brand Loyalty. Journal of Marketing Management, 32 (5-6), 558-578.

Liu, F., Li, J., Mizerski, D \& Soh, H. (2012). Self-Congruity, Brand Attitude, And Brand Loyalty: A Study on Luxury Brands. EuropeanJournal of Marketing, 46 (7-8), 922-937.

Liua, X., Shinb, H., \& Burn, A. C. (2021). Examining The Impact of Luxury Brand's Social Media Marketing on Customer Engagement: Using Big Data Analytics And Natural Language Processing. Journal of Business Research, 125; 815-826.

Lujja, A., \&Özata, F. Z. (2017). The Consequences of Consumer Engagement in Social Networking Sites. Business and Economics Research Journal, 8 (2), 275-291.

McKnight, D.H, \&Chervany, N.L. (2002). What Trust Means in E-commerce Customer Relationships: An İnterdisciplinary Conceptual Typology. International Journal of Electronic Commerce, 6 (2), 35-59.

Muchardie, B. G., Ydiana, N. H., \& Gunawan, A. (2016). Effect of Socral Media Marketing on Customer Engagement and its Impact on Brand Loyalty in Caring Colours Cosmetics, Martha Tilaar. Binus Business Review, 7 (1), 83-87.

Nunnally, J. (1978). Psychometric Theory, New York: McGraw-Hill.

Oliver, R. (1999). Whence Consumer Loyalty? Journal of Marketing, 63 (4), 33-44.

Orel, F. D., \&Arık, A. (2020). Sosyal Medya Pazarlama Faaliyetlerinin Çevrimiçi Tüketici Katılımı ve Satın Alma Niyeti Üzerindeki Etkisi: Moda Markaları Örneği. Erciyes Üniversitesi Sosyal Bilimler Enstitüsü Dergisi, S. 49, 146-161.

Oyman, M. (2002). Müşteri Sadakati Sağlamada Sadakat Programlarının Önemi. Kurgu Dergisi, 19 (19), 169-185.

Özçifçi, V. (2020). Sosyal Medyanın Tüketicilerin Satın Alma Niyeti Üzerindeki Etkisi. Ahi Evran Üniversitesi Sosyal Bilimler Enstitüsü Dergisi, 6 (1), 206-223.

Panda, T.K., Kumar, A., Jakhar, S., Luthra, S., Garza-Reyes, J. A., Kazacoğlu, I., \&Nayak, S. S. (2020). Social and Environmental Sustainability Model on Consumers' Altruism, Gren Purchase Intention, Gren Brand Loyalty and Evangelism. Journal of Cleaner Production, Vol. 243, 1-11.

Pandey, S., \&Srivastava, S. (2016). Antecedents of Customer Purchase Intention. Journal of Business and Management (IOSR-JBM), 18 (10), 55-82.

Patterson, P., Yu, T., \&Ruyter, K.D. (2006). Understanding Customer Engagement in Services. Proceedings of the Australian and New Zealand Marketing Academy 2006 Conference: Advancing Theory, Maintaining Relevance, Brisbane 
Pjero, E., \& Kercini, D. (2015). Social Media and Consumer Behavior - How Does it Works in Albania Reality? Academic Journal of Interdisciplinary Studies, 4 (3), 141-146.

Porral, C. C., \&Lang M. F. (2015). The Role of Manufacturer Identification, Brand Loyalty and Image on Purchase Intention. British Food Journal, 117 (2), 506-522.

Prentice, C., Han X.Y., Hua L.L., \& Hu L. (2019). The Influence of Identity-Driven Customer Engagement on Purchase Intention. Journal of Retailingband Consumer Services, 47, 339-347.

Rather, A.A., Tehseen S., \&Parrey S. H. (2018). Promoting Customer Brand Engagement and Brand Loyalty Through Customer Brand Identification and Value Congruity. Spanish Journal of Marketing, 22 (3), 321-339.

Santosa, M. H. (2020). A Study of Indonesian High School Students' Perception on the Use of Instagram as English Instructional Media. Humanising Language Teaching, 22 (4), 1-7.

Sheth, S., \&Kim, J. (2017). Social Media Marketing: The Effect of Information Sharing, Entertainment, Emotional Connection and Peer pressure on the Attitude and Purchase Intentions. GSTF Journal on Business Review (GBR), 5 (1), 62-70.

So, K.K.F., King, C., \&Sparks, B. (2014). Customer Engagement With Tourism Brands: Scale Development and Validation. Journal of Hosp. Tour. Res, 38 (3), 304-3029.

Solem, B. A. A. (2016). Influences of Customer Participation and Customer Brand Engagement on Brand Loyalty. Journal of Consumer Marketing, 33 (5), 332-342.

Tafesse, W. (2016). An Experiential Model of Consumer Engagement in Social Media. Journal of Product \& Brand Management, 25 (5), $424-434$.

Ting, D.H, Abbasi, A.Z., \&Ahmed, S. (2020). Examining the Mediating Role of Social Interactivity Between Customer Engagement and Brand Loyalty. Asia Pacific Journal of Marketing and Logistics, 33 (5), 1139-1158.

Toor, A., Husnain, M., \& Hussain, T. (2017). The Impact of Social Network Marketing on Consumer Purchase Intention in Pakistan: Consumer Engagement as a Mediator. Asian Journal of Business and Accounting, 10 (1), 167-199.

Vivek, S.D., Beatty, S.E., \&Morgan, R.M. (2012). Customer Engagement: Exploring Customer Relationships Beyond Purchase. Journal of Marketing Theory and Practice, 20 (2), 122-146.

Wang, J.C., \& Chang, C.H. (2013). How Daring Social Ties and Product-Related Risks Influence Purchase Intentions: A Facebook Experiment. Electronic Commerce Research and Applications, 12 (5), 337-346.

Weman, E. (2011). Consumer Motivations to Join a Brand Community on Facebook. (Master's thesis). Hanken School of Economics, Helsinki.

Yoo, B., \& Donthu, N. (2001). Developing a Scale to Measure the Perceived Quality of an Internet Shopping Site (SITEQUAL). Quarterly Journal of Electronic Commerce, 2 (1), 31-47.

Zeithaml, V., Berry, L., \&Parasuraman, A. (1996). The Behavioral Consequences of Service Quality. Journal of Marketing, 60 (2), 31-46. 